\title{
XXXV. A new theory of galvanism, supported by some experiments and observations made by means of the Calorimotor, a new galvanic instrument; also, a new mode of decomposing potash extemporaneously. Read before the academy of Natural Sciences, Philadelphia
}

\section{Robert Hare M.D.}

To cite this article: Robert Hare M.D. (1819) XXXV. A new theory of galvanism, supported by some experiments and observations made by means of the Calorimotor, a new galvanic instrument; also, a new mode of decomposing potash extemporaneously. Read before the academy of Natural Sciences, Philadelphia, Philosophical Magazine Series 1, 54:257, 206-215, DOI: $10.1080 / 14786441908652213$

To link to this article: http://dx.doi.org/10.1080/14786441908652213

Published online: 23 Jul 2009.

Submit your article to this journal $\sqsubset$

山 Article views: 2 
tains it. The original passage is, "Hunc lapidem (viz. the belemnite) plurimis in locis apud nos quam copiosissimè inveni ; at perpetuo in terrâ rubrâ ferrê̂ sive ea mollior glela sive saxea sit." Now follows the translation: "This stone is found very abundantly in many places among us in a red ferruginous earth, either in softer or more stony masses."

In one of my Essays I have mentioned the name of Mr. Martin first, and that of $\mathrm{Mr}$. Smith afterwards, to the great displeasure of my commentator, who thinks I should have mentioned the name of Mr. Sinith first, and that of Mr. Martin afterwards; for what reason $I$ am utterly at a loss to imagine, unless, because in reading the passage my commentator has overlooked the words "at an early period," as his friend has overlooked the "at perpetuo." I really feel obliged to one, who, in questioning my fairness, affords so characteristic a specimen of his own.

In the same volume I have adduced my reasons for doubting the intimate and invariable connexion which has been said to exist between contenporaneous strata and their fossils. Mr. Farey, an advocate for that connexion, which he maintains was first laid down by Mr. Smith, does not undertake to prove its correctness; he contents himself with assuming it. But as the assumption of a contested fact is apt to imply, not the absence of doubt, but the absence of evidence, I am somewhat curious to be informed how far Mr. Farey's theory on this subject is borne out by his experience. He has examined Derbyshire with very laudable industry; will he take the trouble to mention, what the fossils are, by which he is enabled to distinguish the different limestones in that county, or the different sandstones, or the different shales? There will be time to discuss the originality of the doctrine when its truth is established. If its truth cannot be established, I beg very respectfully to ask Mr. Farey, whether he can hope to exalt the character of his teacher by proving him the first discoverer of that which does not exist?

I am, sir, your obedient servalut,

G. B. Greenough.

XXXV. A new Theory of Galvanism, supported by some Experiments and Observations made by menns of the Calorimotor, a new Galvanic Instrument; also, a new Mode of decomposing Potash extemporaneously. Read before the Academy of $\mathrm{Na}$ iural Sciences, Philadelphia. By Robert Hare, M.D. Professor of Chemistry in the Medical Department of the University of Pennsylvania, and Member of several Learned Socisties.

I HAVE for some time been of opinion that the principle extricated by the Voltaic pile is a compound of caloric and electricity, 
tricity, both being original and collateral products of Galvanic action.

The grounds of this conviction, and some recent experiments confirming it, are stated in the following paper.

It is well known that heat is liberated by Voltaic apparatus, in a manner and degree which has not been imitated by means of mechanical electricity; and that the latter, while it strikes at a greater distance, and pervades conductors with much greater speed, can with difficulty be made to effect the slightest decompositions. Wollaston, it is true, decomposed water by means of it; but the experiment was performed of necessity on a seale too minute to permit of his ascertaining, whether there were any divellent polar attractions exercised towards the atoms, as in the case of the pile. The result was probably caused by mechanical concussion, or that process by which the particles of matter are dispersed when a battery is discharged through them. The opinion of Dr. Thomson, that the fluid of the pile is in quantity greater, in intensity less, than that evolved by the machine, is very inconsistent with the experiments of the chemist above mentioned, who, before he could effect the separation of the elements of water by mechanical electricity, was obliged to confine its emission to a point imperceptible to the naked eve. If already so highly jntense, wherefore the necessity of a further concentration? Besides, were the distinction made by Dr. Thomson correct, the more concentrated fluid generated by a Galvanic apparatus of a great many sinall pairs, ought most to resemble that of the ordinary electricity; but the opposite is the case. The ignition produced by a few large Galvanic plates, where the intensity is of course low, is a result most analogous to the chemical effects of a common electrical battery. According to my view, caloric and electricity may be distinguished by the following characteristics. The former permentes all matter more or less, though with very different degrees of facility. It radiates through air, with immeasurable celerity, and, distributing itself in the interior of bodies, communicates a resiprocally repellent power to atoms, but not to masses. Electricity does not radiate in or through any matter; and while it pervades some bodies, as metals, with almost infinite velocity; by others it is so far from being conducted, that it can only pass through them ty a fracture or perforation. Distributing itself over surfaces only, it causes repulsion between masses, but not between the particles of the same mass. The disposition of the last mentioned principle to get off by neighbouring conductors, and of the other to combine with the adjoining matter or to escape by radiation, would prevent them from being collected at the positive pole, if not in combination with each other. Were it not for a modification 
cation of their properties, consequent to some such union, they could not, in piles of thousands of pairs, be carried forward through the open air and moisture; the one so well calculated to conduct away electricity, the other so favourable to the radiation of caloric.

Pure electricity does not expand the slips of gold leaf, between which it causes repulsion, nor does caloric cause any repulsion in the ignited masses which it expands. But as the compound fuid extricated by Galvanic action, which I shall call electrocaloric, distributes itself through the interior of bodies, and is evidently productive of corpuscular repulsion, it is in this respect more allied to caloric than to electricity.

It is true, that when common electricity causes the deflagration of metals, as by the discharge of a Leyden jar, it must be supposed to insinuate itself within them, and cause a re-action between their particles. But in this case, agreeably to my hypothesis, the electric fiuid combines with the latent caloric previously existing there, and, adding to its repulsive agency, causes it to overpower cohesion.

Sir Humphry Dayy was so much at a loss to account for the continued ignition of wire at the poles of a Voltaic apparatus, that he considers it an objection to the materiality of heat; since the wire could not be imagined to contain sufficient caloric to keep up the emission of this principle for an unlimited time. But if we conceive an accumulation of heat to accompany that of electricity throughout the series, and to be propagated from one end to the other, the explanation of the phanomenon in question is attended by no difficulty.

The effect of the Galvanic fivid on charcoal is very consistent with my views, since, next to metals, it is one of the best conductors of electricity, and the worst of beat, and would therefore arrest the last, and allow the other to pass on. Though peculiarly liable to intense ignition when exposed between the poles of the Voltaic apparatus, it seems to me it does not display this characteristic with common electricity. According to Sir Humphry Davy, when in connexion with the positive pole, and communicating by a platina wire with the negative pole, the latter is less heated than when, with respect to the poles, the situation of the wire and charcoal is reversed. The rationale is obvious : charcoal being a bad conductor, and a good radiator, prevents the greater part of the heat from reaching the platina, when placed between it and the source whence the heat flows.

I had observed that as the number of pairs in Volta's pile had been extended, ant their size and the energy of interposed agents lessened, the ratio of the electrical effects to those of heat had increased; till in De Luc's column they had become completely 
predominant; and, on the other hand, when the pairs were made larger and fewer, (as in Children's apparatus,) the calorific influence had gained the ascendancy. I was led to go further in this way, and to examine whether one pair of plates of enormous size, or what might be equivalent thereto, would not exhibit heat more purely, and demonstrate it equally with the electric fluid, a primary product of Galvanic combinations. The elementary battery of Wollaston, though productive of an evanescent ignition, was too minute to allow him to make the observations which 1 had in view.

Twenty copper and twenty zinc plates, about nineteen inches square, were supported vertically in a frame, the different metals alternating at one half-inch distance from each other. All the plates of the same kind of metal were soldered to a common slip, so that each set of homogeneous plates formed one continuous metallic superficies. When the copper and zinc surfaces thus formed are united by an intervening wire, and the whole immerged in an acid or aceto-saline solution, in a vessel devoid of partitions, the wire becomes intensely ignited; and when hydrogen is liberated it usually takes fire, producing a very beautiful undulating or coruscating flame.

I am confident, that if Volta and the other investigators of Galvanism, instead of multiplying the pairs of Galvanic plates, had sought to increase the effect by enlarging one pair as I have done, (for I consider the copper and zinc surfaces as reduced to two by the connexion,) the apparatus would have been considered as presenting a new mode of evolving heat as a primary effect independently of electrical influence. There is no other indication of electricity when wires from the two surfaces touch the tongue, than a slight taste, such as is excited by small pieces of zinc and silver laid on it and under it, and brought into contact with each other.

It was with a view of examining the effects of the proximity and alternation in the heterogeneous plates, that $I$ had them cut into separate squares. By having them thus divided, 1 have been enabled to ascertain, that when all of one kind of metal are ranged on one side of the frame, and all of the other kind on the other side of it, the effect is no greater than might be expected from one pair of plates.

Volta, considering the changes consequent to his contrivance as the effect of a movement in the electric fluid, called the process electro-motion, and the plates producing it electro-motors. But the phænomena show that the plates, as I have arranged them, are calori-motors, or heat-movers, and the effect calorimotion. That this is a new view of the subject, may ibenferred from the following passage in Davy's Elements. That great

Vol. 54. No. 257. Sept. 1819. 
chemist observes, "When very small conducting surfaces are used for conveying very large quantities of electricity, they become ignited; and of the differet conductors that have been compared, charcoal is most easily heated by electrical discharges*, next iron, platina, gold, then copper, and lastly zinc. The phænomena of electrical ignition, whether taking place, in gaseous, fluid, or solid bodies, always seem to be the result of a violent exertion of the electrical attractive and repellent powers, which may be connected with motions of the particles of the substances affected. That no subtile fluid, such as the matter of heat has been imagined to be, can be discharged from these substances, in consequence of the effect of the electricity, seems probable, from the circumstance, that a wire of platina may be preserved in a state of intense ignition in vacuo, by means of the Voltaic apparatus, for an unlimited time; and such a wire cannot be supposed to contain an inexhaustible quantity of subtile matter."

But I demand, where are the repellent and attractive powers to which the ignition produced by the Calorimotor can be attributed? Besides, 1 would beg leave respectfully to inquire of this illustrious author, whence the necessity of considering the heat evolved under the circumstances alluded to as the effect of the electrical fluid; or why we may not as well suppose the latter to be excited by the heat? It is evident, as he observes, that a wire cannat be supposed to contain an inexhaustible supply of matter, however subtile; but wherefore may not one kind of subtile matter be supplied to it from the apparatus as well as another? especially, when to suppose such a supply is quite as inconsistent with the characteristics of pure electricity, as with those of pure caloric?

It is evident from Mr. Children's paper in the Annals of Philosophy, on the subject of his large apparatus, that the ignition produced by it was ascribed to electrical excitement.

For the purpose of ascertaining the necessity of the alternation and proximity of the copper and zinc plates, it has been mentioned that distinct square sheets were employed. The experiments have since been repeated and found to succeed by Dr. Patterson and $\mathrm{Mr}$. Lukens; by means of two continuous sheets, one of zinc, the other of copper, wound into two concentric coils or spirals. This, though the circumstance was not known to them, was the form I had myself proposed to adopt, and had suggested as a convenient for a Galvanic apparatus to several friends at the beginning of the wintert; though the consideration above

* The conclusions are drawn from experiments made by the electricity of the Voltaic apparatus.

$\uparrow$ Especially to Dr. T. P. Jones, and Mr. Rubens Peale, who remember the suggestion. 
stated induced me to prefer for a first experiment a more manageable arrangement.

Since writing the above, I find that when, in the apparatus of twenty copper and twenty zinc plates, ten copper plates on one side are connected with ten zinc on the other, and a communication made between the remaining twenty by a piece of iron wire about the eighth of an inch in diameter, the wire enters into a vivid state of combustion on the immersion of the plates. Platina wire equal to No. 18 (the largest I had at hand) is rapidly fused if substituted for the iron.

This arrangement is equivalent to a battery of two large Galvanic pairs; excepting that there is no insulation, all the plates being plunged in one vessel. I have usually separated the pairs by a board extending across the frame merely.

Indeed, when the forty plates were successively associated in pairs, of copper and zinc, though suspended in a fuid held in a common recipient without partitions, there was considerable intensity of Galvanic action. This shows that, independently of any power of conducting electricity, there is some movement in the solvent fuid which tends to carry forward the Galvanic principle from the copper to the zinc end of the series. I infer that electro-caloric is communicated in this case by circulation, and that in non-elastic fluids the same dificulty exists as to its retrocession from the positive to the negative end of the series, as is found in the downward passage of caloric through them.

It ought to be mentioned, that the connecting wire shonld be placed between the heterogeneous surfaces before their immersion, as the most intense ignition takes place immediately afterwards. If the connexion be made after the plates are immersed, the effect is much less powerful; and sometimes after two or three immersions the apparatus loses its power, though the action of the solvent should become in the interim much more violent. Without any change in the latter, after the plates have been for some time suspended in the air, they regain their efficacy. I had observed in a Galvanic pile of three hundred pairs of two inches square, a like consequence resulting from a simultaneous immersion of the whole*. The bars holding the plates were balanced by weights, as window sashes are, so that all the plates could be very quickly dipped. A platina wire, No. 18, was fused into a globule, while the evolution of potassium was demonstrated by a rose-coloured flame arising from some potash which had been placed between the poles. The heat however diminished in a few seconds, though the greater extrication of hydrogen from the plates indicated a more intense chemical action.

Agreeably to an observation of Dr. Patterson, electrical ex* See Plate IIr. fig. 3.

O 2

citement 
citement may be detected in the apparatus by the condensing electroscope; but this is no more than what Volta observed to be the consequence of the contact of heterogeneous metals.

The thinnest piece of charcoal intercepts the calorific agent, whatever it may be. In order to ascertain this, the inside of a hollow brass cylinder, having the internal diameter two inches, and the outside of another smaller cylinder of the same substance, were made conical and correspondent, so that the greater would contain the less, and leave an interstice of about one-sixteenth of an inch between them. This interstice was filled with wood, by plugging the larger cylinder with this material, and excavating the plug till it would permit the smaller brass cylinder to be driven in. The excavation and the fitting of the cylinders was performed accurately by means of a turning lathe. The wood in the interstice was then charred by exposing the whole covered by sand in a crucible to a red heat. The charcoal, notwithstanding the shrinkage consequent to the fire, was brought into complete contact with the inclosing metallic surfaces by pressing the interior cylinder further into the exterior one.

Thus prepared, the exterior cylinder being made to touch one of the Galvanic surfaces, and a wire brought from the other Galvanic surface into contact with the outside cylinder, was not affected in the least, though the slightest touch of the interior one caused ignition. The contact of the charcoal with the containing metals probably took place throughout a surface of four square inches, and the wire was not much more than the hundredth part of an inch thick; so that, unless it were to conduct electricity about forty thousand times better than the charcoal, it ought to have been heated, if the calorific influence of this apparatus result from electrical excitement.

I am led finally to suppose, that the contact of dissimilar metals, when subjected to the action of solvents, causes a movement in caloric as well as in the electric fluid, and that the phænomena of Galvanism, the unlimited evolution of heat by friction, the extrication of gaseous matter without the production of cold, might all be explained by supposing a combination between the fluids of heat and electricity. We find scarcely any two kinds of ponderable matter which do not exercise more or less affinity towards each other. Moreover, imponderable particles are supposed highly attractive of ponderable ones. Why then should we not infer the existence of similar affinities between imponderable particles reciprocally? That a peculiar combination between heat and light exists in the solar beams, is evident from their not imparting warmth to a lens through which they may pass, as do those of our culinary fires.

Under this view of the case, the action of the poles in Gal- 
vanic decomposition is one of complex affinity. The particles of compounds are attracted to the different wires agreeably to their susceptibilities to the positive and negative attraction; and the caloric, leaving thel electric fluid with which it had been combined, unites with them at the moment that their electric state is neutralized.

As an exciting fluid, I have usually employed a solution of one part sulphuric acid and two parts muriate of soda with seventy of water; but, to my surprise, I have produced nearly a white heat by an alkaline solution barely sensible to the taste.

For the display of the heat effects, the addition of manganese, red lead, or the nitrats, is advantageous.

The rationale is obvious. The oxygen of these substances prevents the liberation of the gaseous hydrogen, which would carry off the caloric. Adding to diluted muriatic acid, while. acting on zinc, enough red lead to prevent efferrescence, the temperature rose from 70 to 110 Fahrenheit.

The power of the Calorimotor is much increased by having the communication between the different sheets formed by very large strips or masses of metal. Observing this, I rendered the sheets of copper shorter by half an inch, for a distance of four inches of their edges, where the communication was to be made between the zinc sheets; and, vice versâ, the zinc was made in the same way shorter than the copper sheets where these were to com. municate with each other. The edges of the shortened sheets being defended by strips of wood, tin was cast on the intermediate protruding edges of the longer ones, so as to embrace a portion of each equal to about one quarter of an inch by four inches. On one side the tin was made to run completely across, connecting at the same time ten copper and ten zinc sheets. On the other side, there was an interstice of above a quarter of an inch left between the stratum of tin embracing the copper, and that embracing the zinc plates. On each of the approaching terminations of the connecting tin strata was soldered a kind of forceps, formed of a bent piece of sheet brass furnished with a screw for pressing the jaws together. The distance between the different forceps was about two inches. The advantage of a very close contact was made very evident by the action of the screws; the relaxation or increase of pressure on the connecting. wire by turning them being productive of a correspondent change in the intensity of ignition.

It now remains to state, that by means of iron ignited in this apparatus, a fixed alkali may be decomposed extemporaneously. If a connecting iron wire, while in combustion, be touched by the hydrate of potash, the evolution of potassium is demonstrated by a rose-coloured flame. The alkali may be applied to the wire in 
small pieces in a flat hook of sheet iron. But the best mode of application is by means of a tray made by doubling a slip of sheet iron at the ends, and leaving a receptacle in the centre, in which the potash may be placed covered with filings. This tray being substituted for the connecting wire, as soon as the immersion of the apparatus causes the metal to burn, the rose-coloured flame appears; and if the residuum left in the sheet iron be afterwards thrown into water, an effervescence sometimes ensues.

I have ascertained that an iron heated to combustion, by a blacksmith's forge fre, will cause the decomposition of the hyirat of potash.

The dimensions of the Calorimotor may be much reduced without proportionably diminishing the effect. I have one of sixty plates within a cubic foot, which burns off No. 16, iron wire A good workman could get 120 plates of a foot square within a hollow cube of a size no larger.-But the inflammation of the hydrogen which gives so much splendour to the experiment. can only be exhibited advantageously on a large scale.

Explanation of the Plate (III).-A a, fig. Ist, two cubical vèssels, 20 inches square, inside. $\mathrm{b} b \mathrm{~b}$ b a frame of wood containing 20 sheets of copper, and 20 sheets of zine, alternating with each other, and about half an inch apart. T T $t \mathrm{t}$ masses of tin cast over the protruding edges of the sheets which are to communicate with each other. Fig. 2 . represents the mode in which the junction between the various sheets and tin masses is effected. Between the letters $z \mathrm{z}$, the zinc only is in contact with the tin asses. Between $\mathrm{c} c$, the copper alone touches. It may be observed, that, at the back of the frame, ten sheets of copper between $\mathrm{c} c$, and ten sheets of zinc between $\mathrm{z} z$, are made to communicate by a common mass of tin extending the whole length of the frame, between $T$ ' $T$ : but in front, as in fig. $I$, there is an interstice between the mass of tin connecting the ten copper sheets, and that connecting the ten zinc sheets. The screw forceps, appertaining to each of the tin masses, may be seen on either side of the interstice; and likewise a wire for ignition held between them. The application of the rope, pulley, and weights is obvious. The swivel at $\mathbf{S}$ permits the frame to be swung round and lowered into water in the vessel a, to wash off the acid, which, after immersion in the other vessel, might continue to act on the sheets, encrusting them with oxide. Between $p p$ there is a wooden partition which is not necessary, though it may be beneficial.

Fig.3. represents an apparatus alluded to $p .211$.-It consists of a couronne des tasses, reduced to a form no less compact than 
that of the trough ; hollow parallelopipeds of glass are substituted for tumblers or cells. The plates are suspended to bars counterpoised like window sashes.

The advantages are as follow: The material is one of the best non-conductors, is easily cleansed, and is the most impervious to solvents. The fracture of one of the cups is easily remedied by a supernumerary. They may be procured (as in the United States) where porcelain caunot be had. The shock from 300 pairs is such as few will take a second time : some of the effects have already been stated *.

XXXVI. On Friction in Machinery. By Mr. Henry Meikle. To $M r$. Tilloch. 35, Berners Street, Aug. $27,1819$.
SIR, $-A_{s}$ hinted at the conclusion of my miscellaneous remarks on friction, carriages, \&c. in your Number for March, I again venture to resume that inexhaustible subject.

From the very accurate experiments of Professor Vince and M. Coulonb, it appears that, on hard bodies, friction is an uniformly retarding force; or, that it is constant during all the changes of an uniformly varied motion. This is, perhaps, the most valuable and general mode of experimenting, in order to discover the laws of friction, so far as the velocity is concerned; because, from it, we learn that friction is, cceleris paribus, the same for all the different uniform velocities which do not exceed the greatest attained in the experiment. We must not, however, like Chemists with their laws of expansion and temperature, suppose that friction is the same for velocities greater than those experimented on. Though this seems probable, it is not certain; and to presume on it, we might meet with the same downfall as the faneiful laws of temperature did when they attempted to soar above the ken of observation.

I formerly noticed that, on account of heat, frietion sometimes increases a little with the velocity. This, the experiments referred to, were hardly calculated to detect, as it is not likely they were continued long enough to accumulate heat sufficient - to affect the result. But there is, perhaps, some ground for suspecting that the friction of bodies which have long rubbed on each other, is somewhat different from the frietion of those that only pass a few trials for the sake of experiment. I have often thought that the difference between the results obtained by Professor Vince and $M$. Coulomb, relating to the pressure, was probably owing to causes of this nature.

* The glasses may be had by applying to Edw. A. Pearson, No. 71, Cornhill, Boston. 